\title{
Regional migratory osteoporosis complicated by surgical treatment: Case report
}

\author{
Carlo Cataldi ${ }^{1}$, Nicola Bianchi ${ }^{2 *}$, Nicola Mondanelli ${ }^{1}$, Fabio Moreschini ${ }^{1}$, Vanna Bottai ${ }^{2}$, Stefano Giannotti ${ }^{1}$ and Rodolfo Capanna $^{2}$ \\ ${ }^{1}$ Department of Orthopaedic and Trauma Surgery, University of Siena, Italy \\ ${ }^{2}$ Department of Orthopaedic and Trauma Surgery, University of Pisa, Italy
}

\begin{abstract}
Introduction: Regional migratory osteoporosis (RMO) is an uncommon self-limiting disease characterized by migrating arthralgia involving the weight-bearing joints of the lower limbs, appearing on imaging as migrating bone marrow edema associated with osteoporosis.

Case: We describe a shank and ankle RMO case, probably aggravated by surgical treatment of the homolateral knee.

Discussion: At first, we excluded the presence of thrombosis, superficial or deep infection, neurological pathology and other organic syndrome; then we diagnosed a case of RMO according with the symptoms, the migrating distribution "proximal to distal" and the atraumatic onset. The knee surgical treatment likely aggravated the pre-existent RMO.
\end{abstract}

Conclusion: RMO is an uncommon disease, which is often under-diagnosed.

\section{Introduction}

For the first time, in 1959, Curtiss and Kincaid [1] described a syndrome of transient demineralization of the hip in pregnant women (transient osteoporosis of the hip, TOH). RMO was first described by Duncan, et al. [2]. Since then, various terms were proposed in order to describe the common benign clinical and imaging conditions of bone marrow edema. Subsequently, these clinical entities were included under the general term of "bone marrow edema syndrome" (BMES) [3]. Now BMES represents a distinct entity with specific clinical and imaging features, but some authors support that this syndrome should be a variant of algodystrophy or an abortive form of osteonecrosis [4].

Many pathogenetic hypotheses have been proposed but the etiology of these forms remains unknown. Many cases are misdiagnosed due to the lack of specific symptoms and the rarity of the disease. The main characteristic in common with CPRS is the chronic pain. Instead, characteristics missing in CPRS are: absent history of trauma or triggering events, the extremely rare involvement of the upper limbs, the absence of skin dystrophic changes and vasomotor alterations, the recurring and migrant nature and the complete restitution ad integrum (absent in cases of algodystrophy non-promptly recognized and treated) [5].

Laboratory findings usually are not useful to the diagnosis. Standard radiographs could be normal in early phases. It can reveal bone demineralization at 3-6 weeks from the onset of the symptoms and this alteration may persist after the symptom resolution, also up to 2 years [6].

In the absence of clinical signs (autonomic and dystrophic changes) and radiographic examination findings, it becomes important for a correct assessment, in contrast to CRPS, to perform further investigations such as RMI and scintigraphy. The three-phases bone scan may be positive after a few days from the onset of symptoms. Tc99m-MDP increased uptake representing focal increase in capillary permeability, hyperaemia, and osteoblastic activity. MR imaging scans re- veal low-signal intensity on T1-w images and high signal intensity on STIR or fat-suppressed T2-w images. These changes reflect the increased intra and extracellular fluid of the bone marrow resulting from new bone formation and re- pair processes [6]. The differential diagnosis at MRI scans should be made with infection, osteonecrosis and post-traumatic marrow edema [7].

We describe a shank and ankle RMO case, probably aggravated by surgical treatment of the omolateral knee.

\section{Case report}

A 77-year-old man presented with a 2-months history of right knee pain. There was neither a history of trauma nor risk factors for osteonecrosis. Blood tests for osteo-metabolism, infection index and rheumatic pathologies revealed normal results. Radiographs showed knee osteoarthritis signs (grade II Kellgren-Lawrence).

Furthermore, the patient underwent magnetic resonance (MR) examination that showed a large ill-defined area of increased signal intensity on fat-saturated T2-weighted images consistent with bone marrow edema involving the medial (more) and lateral femoral condyle of the right knee (Figure 1).

${ }^{\star}$ Correspondence to: Nicola Bianchi, Department of Orthopaedic and Trauma Surgery, University of Pisa Italy, E-mail: nicobianchi87@alice.it

Key words: RMO, osteoporosis, algodystrophy, bone marrow edema

Received: October 16, 2018; Accepted: February 18, 2019; Published: February 20, 2019 
Despite the medical treatment (oral analgesia, bisphosphonate and magneto-therapy, clinical symptoms didn't regress after 3 months. A new MR examination showed a complete resolution of bone marrow edema of the knee so that we decided to do a total knee arthroplasty. Two months after surgery there was a complete resolution of the knee pain, but the patient referred a sudden spontaneous pain and swelling in his right foot and ankle, so he underwent haematological exams, peripheral circulation studies (vascular ultrasonography) and radiographs; all the studies showed no abnormalities.

Because of continued pain, the patient underwent foot-ankle magnetic resonance imaging (MRI) which showed bone marrow edema involving the talus (Figure 2). The patient undertook conservative therapy, and symptoms resolved approximately 5 months later. A new MRI also demonstrated a complete resolution of bone marrow edema.

\section{Discussion}

Regional migratory osteoporosis (RMO) is an uncommon selflimiting disease characterized by migrating arthralgia involving the weight-bearing joints of the lower limbs, appearing on imaging as migrating bone marrow edema associated with osteoporosis.

The aetiology of RMO and its relationship to transient osteoporosis of the hip (TOH), transient bone marrow oedema, osteonecrosis and CPRS have been enthusiastically debated [8-10].

People most commonly present with a mono-articular arthralgia, of either acute or insidious onset, that is not related to trauma. Weeks or months later further joints become involved, often as the symptoms in the original joint are waning. Patterns of distribution are variable but sequential proximal to distal joint involvement is typical. The clinical course can last up to 9 months [2,11-16]. Clinical examination often reveals moderate tenderness, joint effusions and swelling, with a near normal range of motion. Weight bearing causes severe pain, often
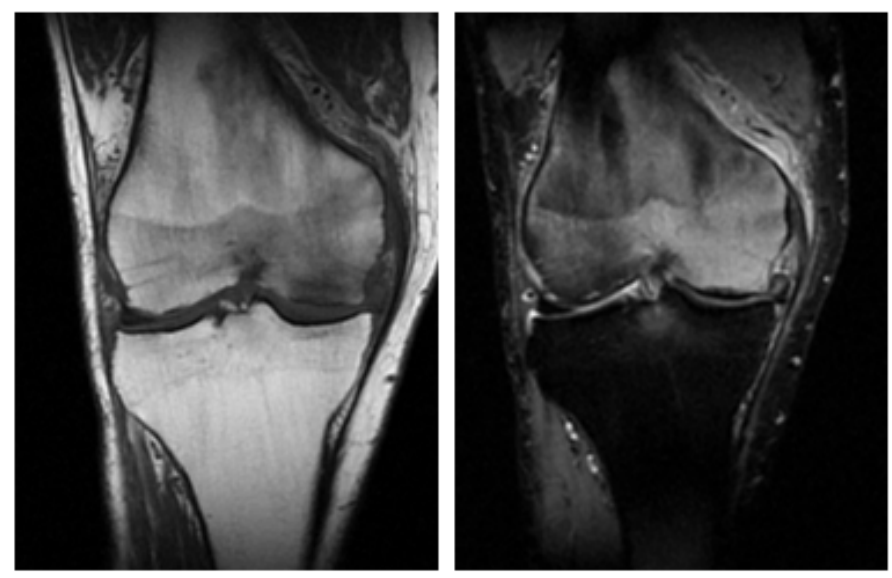

Figure 1. MR examination of medial and lateral femoral condyle of the right knee
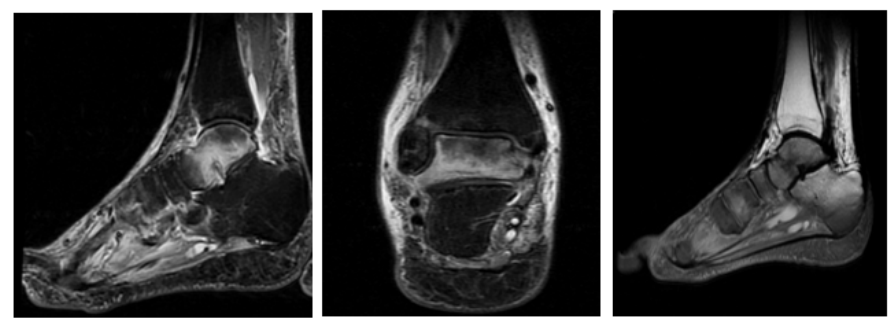

Figure 2. Foot-ankle magnetic resonance imaging which showed bone marrow edema involving the talus making walking difficult or impossible. Treatment is usually expectant, with oral analgesia and non-weight-bearing strategies providing symptomatic relief. Relapse of the disease, following complete resolution of the initial episode, is well documented $[16,17]$.

Plain radiography and bone densitometry demonstrate local osseous demineralization, which can be seen months after the symptoms have resolved. Bone scintigraphy reveals increased radionuclide uptake and magnetic resonance imaging (MRI) shows bone marrow oedema at the symptomatic sites.

\section{All these characteristics are present in our case.}

The first diagnosis wasn't correct; clinical signs and radiological pattern led to the diagnosis of knee arthrosis. The absence of traumatic or triggering event and the lack of skin alterations contributed to confuse the diagnosis. At the beginning the treatment was a conservative one in order to solve the pain and the bone edema and to programme a surgical approach with a knee prosthesis. Anyhow, in the immediate post-surgery period, the patient began to refer the onset, on the same side of the surgery, of shank and ankle pain, paraesthesia, swelling and hyperalgesia. At first, we excluded the presence of thrombosis, superficial or deep infection, neurological pathology and other organic syndrome; then we diagnosed a case of RMO according with the symptoms, the migrating distribution "proximal to distal" and the atraumatic onset. The knee surgical treatment likely aggravated the preexistent RMO.

\section{Conclusion}

$\mathrm{RMO}$ is an uncommon disease, which is often under-diagnosed. It occurs more commonly in men than women. Involvement of secondary joints typically occurs within six months of presentation. It is frequently difficult to diagnose RMO at the initial clinical presentation when unifocal disease is the norm; at this stage in fact the clinical and radiological features are the same as in bone marrow edema syndrome. As the disease progresses, the radiological features of BME and increased bone metabolism, migrate to other juxta articular areas, so that they can be considered to be typical for RMO.

\section{References}

1. Curtiss PH Jr, Kincaid WE (1959) Transitory demineralization of the hip in pregnancy. A report of three cases. J Bone Joint Surg Am 41-41A: 1327-1333. [Crossref]

2. Duncan H, Frame B, Frost H, Arnstein AR (1969) Regional migratory osteoporosis South Med J 62: 41-44. [Crossref]

3. Hofmann S, Kramer J, Vakil-Adli A, Aigner N, Breitenseher M (2004) Painful bone marrow edema of the knee: differential diagnosis and therapeutic concepts. Orthop Clin North Am 35: 321-333.

4. Mailis A, Inman R, Pham D (1992) Transient migratory osteoporosis: a variant of reflex sympathetic dystrophy? Report of 3 cases and literature review. J Rheumatol 19: 758-764.

5. Massara A, Orzincolo C, Prandini N, Trotta F (2005) Transient regional osteoporosis. Reumatismo 57: 5-15. [Crossref]

6. Korompilias AV, Karantanas AH, Lykissas MG, Beris AE (2008) Bone marrow edema syndrome. Skeletal Radiol 38: 425-436. [Crossref]

7. Giannotti S, Bottai V, Dell'Osso G, Bugelli G, Celli F, et al. (2016) Algodystrophy: complex regional pain syndrome and incomplete forms. Clin Cases Miner Bone Metab 13: 11-14.

8. Turner DA, Templeton AC, Selzer PM, Rozenberg AG, Petasnick JP (1989) Femoral capital osteonecrosis: MR finding of diffuse marrow abnormalities without focal lesions. Radiology 171: 135-140.

9. Hofmann S, Engel A, Neuhold A, Leder K, Kramer J, et al. (1993) Bone-marrow oedema syndrome and transient osteoporosis of the hip. An MRI-controlled study of treatment by core decompression. J Bone Joint Surg Br 75: 210-216. [Crossref] 
10. Doury P (1994) Bone-marrow oedema, transient osteoporosis, and algodystrophy. $J$ Bone Joint Surg Br 76: 993-994. [Crossref]

11. Lequesne M (1968) Transient osteoporosis of the hip. A nontraumatic variety of Südeck's atrophy. Ann Rheum Dis 27: 463-471. [Crossref]

12. Hunder GG, Kelly PJ (1968) Roentgenologic transient osteoporosis of the hip. A clinical syndrome? Ann Intern Med 68: 539-552. [Crossref]

13. Rosen RA (1970) Transitory demineralization of the femoral head. Radiology 94: 509-512. [Crossref]
14. Swezey RL (1970) Transient osteoporosis of the hip, foot and knee. Arthritis Rheum 13: 858-868. [Crossref]

15. Pantazapoulos T, Exarchou E, Hartofilakidis-Garofalidis G (1973) Idiopathic transient osteoporosis of the hip. J Bone Joint Surg Am 55: 315-321.

16. McCord WC, Nies KM, Campion DS, Louie JS (1978) Regional migratory osteoporosis. A denervation disease. Arthritis Rheum 21: 834-838. [Crossref]

17. Arnstein A (1972) Regional osteoporosis. Orthop Clin North Am 3: 585-600. [Crossref]

Copyright: (C2019 Cataldi C. This is an open-access article distributed under the terms of the Creative Commons Attribution License, which permits unrestricted use, distribution, and reproduction in any medium, provided the original author and source are credited. 